\title{
Transcendent Philosophy: A Comparative Study on Mulla Sadra and Kant
}

\author{
Fatemeh Sadat Basirizadeh ${ }^{1}$, Narges Raoufzadeh ${ }^{2}$ \\ ${ }^{1}$ Department of English Language and Literature, Science and Research Branch, Islamic Azad University, \\ Tehran, Iran \\ ${ }^{2}$ Department of English Language and Literature, Science and Research Branch, Islamic Azad University, \\ Tehran, Iran \\ nbasiri2002@yahoo.com
}

\begin{abstract}
In this paper, the author attempts to talk about the truth and objectivity of propositions in practical philosophy through a comparative method and the investigation of the philosophical principles of Kant and Mulla Sadra so as to feature the significance of the standards of the Transcendent Philosophy and investigates the view of both philosophers. It is also an investigation of Kant's refusal of presence as a genuine predicate, from one perspective, and Mulla Sadra's affirmation and exhibition of such predicates, on the other.
\end{abstract}

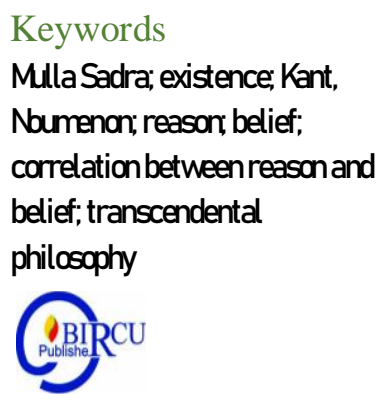

Keywords

Nbumenon reason belief:

correlation between reason and

belief; transcendental

philospphy

\section{Introduction}

It is commonly accepted that most influential philosophers of recent centuries in the east and the west are Molla Sadra-ye-Shirazi, and Kant, the renowned German philosopher, respectively. Since the times f Plato, philosophers claimed that knowledge has a sort of special status that a mere belief lacks. For Kant, a true science must convey universality and necessity where each of its components states knowledge and forms a part of a systematic whole. Thus, for Kant, knowledge is universal and fundamental. Kant's transcendental philosophy crucially involves justification of a priori synthetic knowledge. Specifically, in his epistemological project, knowledge comes from the joint work of the sensibility and the understanding. The sensibility provides the materials but it is the understanding that provides the a priori forms that can organize and process the materials. Kant, the modern philosopher, believes that the development of Man's ethical life depends on structuring an ethical framework the standards of which depend on reason and objectivity. Kant believes he can show that aesthetic judgment is not fundamentally different from ordinary theoretical cognition of nature, and he believes he can show that aesthetic judgment has a deep similarity to moral judgment. For these two reasons, Kant claims he can demonstrate that the physical and moral universes - and the philosophies and forms of thought that present them - are not only compatible, but unified.

The only possible account is that the appearance of purposiveness in nature is conditioned by the supersensible realm underlying nature. But this means that beauty is a kind of revelation of the hidden substrate of the world, and that this substrate has a necessary sympathy with our highest human projects. To this, Kant adds a series of important analogies between the activity of aesthetic judgment and the activity of moral judgment. These analyses lead Kant to claim that beauty is the 'symbol of morality'. Kant's Critique of Judgment (the third Critique) was and continues to be a surprise - even to Kant, for it emerged out of Kant's philosophical activity having not been a part of the original plan. (For an account of Kant's 
first two Critiques, please see the entry on 'Kant's Metaphysics'.) Some philosophers have even claimed that it is the product of the onset of senility in Kant. After initial enthusiasm during the romantic period, the book was relatively ignored until work such as Cassirer's in the early 20th Century. Especially in the last few decades, however, the Critique of Judgment is being increasingly seen as a major and profound work in Kant's output.

Part of the surprise lies in the diversity of topics Kant deals with. For much of the previous two centuries the book was read - and it still is largely read in this way - as a book about aesthetics (the philosophy of the beautiful and the sublime). In fact this type of reading by no means adequately reflects Kant's explicit themes, and is forced to ignore much of the text. Here, we shall try to sketch out the range of topics and purposes (including aesthetics) Kant gives to his third Critique.

Obviously, a precise understanding of every thinker's viewpoint depends on an understanding of his intellectual foundations; therefore, if we want to acquire each scholar's view in a particular domain, first we must consider his intellectual foundations in order to understand his viewpoint. In the present paper aiming to investigate Sadra's thought regarding the language of religion, to achieve Sadra's standpoint in this area, it is necessary to examine the principles and basics of this Transcendent philosophy; since this discussion was never considered in the present form during Sadra's time, thus, first, we will investigate Sadra's philosophical principles and basics relating to this discussion.

According to Mulla Sadra, "existence precedes the essence and is thus principal since something has to exist first and then have an essence." It is notable that for Mulla Sadra this was a question that specifically applied to God and God's position in the universe, especially in the context of reconciling God's position in the Qur'an versus cosmological philosophies of Islam's Golden Era. Mulla Sadra metaphysics gave priority "Ab initio" to existence, over quiddity. That is to say, essences are determined and variable according to existential "intensity", (to use Henry Corbin's definition), and as such essences are not immutable. The advantage to this schema is that it is acceptable to the fundamental statements of the Qur'an, even as it does not necessarily debilitate any previous Islamic philosopher's Aristotelian or Platonic foundations.

Indeed, Mulla Sadra provides immutability only to God, while intrinsically linking essence and existence to each other, and God's power over existence. In so doing, Mulla Sadra simultaneously provided for God's authority over all things, while also solving the problem of God's knowledge of particulars, including those that are evil, without being inherently responsible for them even as God's authority over the existence of existences that provide the framework for evil to exist. This clever solution provides for Freedom of Will, God's Supremacy, the Infiniteness of God's Knowledge, the existence of Evil, and a definition of existence and essence which leaves two inextricably linked insofar as Man is concerned, but fundamentally separate insofar as God is concerned. Perhaps most importantly, the Primacy of Existence solution provides the capacity for God's Judgement without God being directly, or indirectly, affected by the evil being judged. God does not need to possess Sin to know Sin: God is able to judge the intensity of Sin as God perceives Existence. One result of this Existentialism is "The unity of the intellect and the intelligible" (Arabic: Ittihad al-Aaqil wa 1-Maqul. As Henry Corbin describes:

All the levels of the modes of being and perception are governed by the same law of unity, which at the level of the intelligible world is the unity of intellection, of the intelligizing subject, and of the Form intelligized the same unity as that of love, lover and beloved. Within this perspective we can perceive what Sadra meant by the unitive union of 
the human soul, in the supreme awareness of its acts of knowledge, with the active Intelligence which is the Holy Spirit. It is never a question of an arithmetical unity, but of an intelligible unity permitting the reciprocity which allows us to understand that, in the soul which it metamorphoses, the Form - or Idea — intelligized by the active Intelligence is a Form which intelligizes itself, and that as a result the active Intelligence or Holy Spirit intelligizes itself in the soul's act of intellection. Reciprocally, the soul, as a Form intelligizing itself, intelligizes itself as a Form intelligized by the active Intelligence.

For Mulla Sadra a true statement is a statement that is true to the concrete facts in existence. He held a metaphysical and not a formal idea of truth, claiming that the world consists of mind-independent objects that are always true and truth is not what is rationally acceptable within a certain theory of description. In Mulla Sadra's view one cannot have access to the reality of being: only linguistic analysis is available. This theory of Truth has two levels: the claim that a proposition is true if it corresponds to things in reality; and that a proposition can be true if it conforms with the actual thing itself.

\section{Research Method}

In the Critique of Pure Reason Kant argues that space and time are merely formal features of how we perceive objects, not things in themselves that exist independently of us, or properties or relations among them. Objects in space and time are said to be "appearances", and he argues that we know nothing of substance about the things in themselves of which they are appearances. Kant calls this doctrine (or set of doctrines) "transcendental idealism", and ever since the publication of the first edition of the Critique of Pure Reason in 1781, Kant's readers have wondered, and debated, what exactly transcendental idealism is, and have developed quite different interpretations. Some, including many of Kant's contemporaries, interpret transcendental idealism as essentially a form of phenomenalism, similar in some respects to that of Berkeley, while others think that it is not a metaphysical or ontological theory at all. There is probably no major interpretive question in Kant's philosophy on which there is so little consensus. This entry provides an introduction to the most important Kantian texts, as well as the interpretive and philosophical issues surrounding them. One promising place to begin understanding transcendental idealism is to look at the other philosophical positions from which Kant distinguishes it. In the "Fourth Paralogism", he distinguishes transcendental idealism from transcendental realism:

To this [transcendental] idealism is opposed transcendental realism, which regards space and time as something given in themselves (independent of our sensibility). The transcendental realist therefore represents outer appearances (if their reality is conceded) as things in themselves [Dinge an sich selbst], which would exist independently of us and our sensibility and thus would also be outside us according to pure concepts of the understanding. (Critique of Pure Reason,369)

Transcendental realism, according to this passage, is the view that objects in space and time exist independently of our experience of them, while transcendental idealism denies this. This point is reiterated later in the Critique when Kant writes:

We have sufficiently proved in the Transcendental Aesthetic that everything intuited in space or in time, hence all objects of an experience possible for us, are nothing but appearances, i.e., mere representations, which, as they are represented, as extended beings or series of alterations, have outside our thoughts no existence grounded in 
itself. This doctrine I call transcendental idealism. The realist, in the transcendental signification, makes these modifications of our sensibility into things subsisting in themselves, and hence makes mere representations into things in themselves. (519)

Kant also distinguishes transcendental idealism from another position he calls "empirical idealism":

One would also do us an injustice if one tried to ascribe to us that long-decried empirical idealism that, while assuming the proper reality of space, denies the existence of extended beings in it, or at least finds this existence doubtful, and so in this respect admits no satisfactorily provable distinction between dream and truth. As to the appearances of inner sense in time, it finds no difficulty in them as real things, indeed, it even asserts that this inner experience and it alone gives sufficient proof of the real existence of their object (in itself) along with all this time-determination. (519)

Empirical idealism, as Kant here characterizes it, is the view that all we know immediately (non-inferentially) is the existence of our own minds and our temporally ordered mental states, while we can only infer the existence of objects "outside" us in space. Since the inference from a known effect to an unknown cause is always uncertain, the empirical idealist concludes we cannot know that objects exist outside us in space. Kant typically distinguishes two varieties of empirical idealism: dogmatic idealism, which claims that objects in space do not exist, and problematic idealism, which claims that objects in space may exist, but we cannot know whether they do. Although he is never mentioned by name in the A Edition, Berkeley seems to be Kant's paradigm dogmatic idealist, while Descartes is named as the paradigm problematic idealist.

Transcendental idealism is a form of empirical realism because it entails that we have immediate (non-inferential) and certain knowledge of the existence of objects in space merely through self-consciousness:

[...] external objects (bodies) are merely appearances, hence also nothing other than a species of my representations, whose objects are something only through these representations, but are nothing separated from them. Thus external things exist as well as my self, and indeed both exist on the immediate testimony of my selfconsciousness, only with this difference: the representation of my Self, as the thinking subject is related merely to inner sense, but the representations that designate extended beings are also related to outer sense. I am no more necessitated to draw inferences in respect of the reality of external objects than I am in regard to the reality of my inner sense (my thoughts), for in both cases they are nothing but representations, the immediate perception (consciousness) of which is at the same time a sufficient proof of their reality. (370-1)

Merely through self-conscious introspection I can know that I have representations with certain contents and since appearances are "nothing other than a species of my representations" this constitutes immediate and certain knowledge of the existence of objects in space.Understanding transcendental idealism requires understanding the precise sense in which things in themselves are, and appearances are not, "external to" or "independent" of the mind and Kant draws a helpful distinction between two senses in which objects can be "outside me":

But since the expression outside us carries with it an unavoidable ambiguity, since it sometimes signifies something that, as a thing in itself [Ding an sich selbst], exists distinct from us and sometimes merely that belongs to outer appearance, then in order to escape 
uncertainty and use this concept in the latter significance - in which it is taken in the proper psychological question about the reality of our outer intuition-we will distinguish empirically external objects from those that might be called "external" in the transcendental sense, by directly calling them "things that are to be encountered in space". (373)

In the transcendental sense, an object is "outside me" when its existence does not depend (even partly) on my representations of it. The empirical sense of "outside me" depends upon the distinction between outer and inner sense. Inner sense is the sensible intuition of my inner states (which are themselves appearances); time is the form of inner sense, meaning that all the states we intuit in inner sense are temporally ordered. Outer sense is the sensible intuition of objects that are not my inner states; space is the form of outer sense. In the empirical sense, "outer" simply refers to objects of outer sense, objects in space. Transcendental idealism is the view that objects in space are "outer" in the empirical sense but not in the transcendental sense. Things in themselves are transcendentally "outer" but appearances are not.

There are realities in the external world. These realities are not more than one unity and one thing. This is the human mind that divides the external reality into two points of essence and existence (being). Because of this, it becomes necessary that the external reality also be both unique and not unique. According to the previous premises, wisdom commands that one of these dimensions either essence or being, is real and exists objectively. After an intellectual analysis that, for example, human nature is a talking animal, it leads to a conclusion that in nature there is no place for being and realization. The reason states that it has been given reality by being created by the creator. Essence, by itself, and even regarding its relation to the creator, cannot be as a fact, because it entails revolution in essence by itself which is impossible unless something is given to essence so that it could not be nothing. Hence, it is being that essence could be realized by endowment of being and existence.

\section{Discussion}

Immanuel Kant is an 18th century German philosopher whose work initiated dramatic changes in the fields of epistemology, metaphysics, ethics, aesthetics, and teleology. Like many Enlightenment thinkers, he holds our mental faculty of reason in high esteem; he believes that it is our reason that invests the world we experience with structure. In his works on aesthetics and teleology, he argues that it is our faculty of judgment that enables us to have experience of beauty and grasp those experiences as part of an ordered, natural world with purpose. The first thing to note is Kant claims that reason is the arbiter of truth in all judgments empirical as well as metaphysical. Unfortunately, he barely develops this thought, and the issue has attracted surprisingly little attention in the literature. Along these lines, it would be free from any sort of subjectivity and individual inclination, which harmed the ethical arrangement of his period. The main suggestion which appreciates these highlights is the absolute objective. Presently, the issue is the manner by which Kant legitimizes the objectivity and truth of this goal. The same principle of reasoned unity also applies to judgments that are not readily decided by everyday experience. Why are we sure that the sun does not orbit the earth, despite all appearances? To answer such questions, we need to consider reason's role in scientific knowledge. Kant (1990) in Kant's theory of judgment claims that reason is "the origin of certain concepts and principles" (Paul Guyer and Allen W. Wood, 103-104). Kant claims that reason is "the origin of certain concepts and principles" (355). Independent from those of sensibility and understanding. Kant refers to these as 
"transcendental ideas" or "ideas of pure reason". And he now defines reason as a "faculty of principles" or the "faculty of the unity of the rules of understanding under principles" (358). In practical philosophy, the ethical subject gives law to herself as well. So the ethical subject is a lawgiver. But the two laws that the cognitive subject and the practical subject give are of fundamentally different types. The laws of nature are deterministic causal laws, but the laws of actions are the laws of freedom. The human knowledge is confined to the deterministic natural world but the ethical subject is able to act freely beyond nature. Thus, there arises a discrepancy between nature and freedom. In this way, we can see that there emerges a cleavage between theoretical reason and practical reason in Kant's project. Thus, in response to the question "What may I hope?" Kant answers that we human beings may hope that our souls are immortal and that there really is a God who designed the world in accordance with principles of justice. (Critique of Pure Reason, 832 - 847).

Another inquiry is the way this issue is replied in Mulla Sadra's Islamic logic. In his Critique of Practical Reason, Kant keeps up that functional issues are established in the ethical law and attempts to legitimize them by turning to pragmatic reason and the idea of opportunity. In spite of the fact that Kant's talks in the field of rationality of morals continue in a manner to show nomena and, especially, freedom, he considers them to be among axioms. This implies the practical reason and opportunity just legitimize the useful plausibility of good experience and other commonsense fields. In other words, conceding the truth of the brains and opportunity is simply founded on belief and faith, therefore, moral recommendations are judicious as opposed to cognitional. In Mulla Sadra's Transcendent Philosophy, practical propositions in individual and social fields are created dependent on practical reason while attending of its association with hypothetical reason. In addition, the domains of both hypothesis and practice originate from the deepest of the spirit and are known through presential learning. Accordingly, all psychological and judicious recognitions are identified with reality of the great and its evaluations as an ontological issue. Along these lines, the objectivity and truth of these propositions are advocated not founded on specific axioms but rather by falling back on the possibility of the presential knowledge of the universe of fact itself. The Sadraddin Shirazi thoughts in theory are viewed as a standout amongst the most valuable pearls in the treasury of the Muslim idea. Having basically improved an agreeing circle of the philosophical learning he has a place with those logicians who unquestionably involved their very own position in its history. His actual commitment to philosophy brought about setting up the School of Philosophy.

The ideas of Reason and Belief which are believed to be the central issues in S.Shirazi's logic are investigated in the article. It was uncovered a sphere of their inclusion and connection also. The present research is gone for discovering the Truth which can turn into a base for the new logic pattern. The examination depended on the parts of examination, connection just as the philosophical views by Shirazi on the issues of Reason and Belief. These two issues have been interrelated to one another through the history. Because of near studies it was cleared up that in spite of the undeniable contrast between these two categories they have ended up being opposite sides of a similar Truth.

\section{Conclusion}

In conclusion, the subject of "presence as a predicate" "acknowledges an astounding criticalness from the chronicled and close motivation behind view. Kant, the unmistakable German academic stated that presence couldn't be an authentic predicate for its own one of a 
kind subject, since presence isn't a thought that could add anything to an item. Mulla Sadra, the incomparable Muslim Scholar, has recognized the idea of being as an autonomous, and predicative idea. Based on his philosophical position "the principality of being" shows that what is principal in the outside the truth is "presence" as opposed to "quiddity", he is very not quite the same as the philosophical view purpose of Kant. The being that is connected by Mulla Sadra, as other Muslim Logicians, as a predicate in the existential suggestion is entirely unexpected from that of Kant. Molasadra believed that what is in the world, its example is in the spiritual world and what is in spiritual world its example is in the divine world, then it is stated that nothing is created in existence world unless its example is in human being, as Molasadra considered various degrees and inner and outer for the existence, the same degrees are considered for human being. Based on this theory, he attempted that relationship between mind and full unity is not established, recognition and knowledge are not achieved. The human being existence is not limited to nature world, also, it has special signs before this world and after it and in each aspect a form and actuality in accordance with that world, it is obvious that recognizing the reality of such being that is not stopped in a level and is changing always is difficult and this difficulty caused many various views (Molasadra, 343).

\section{References}

Caygill, Haward. (2000). A Kant Dictionary, Blacwell.

Kant, Immanuel. (1996). The Works of Immanuel Kant, translated and edited by Mary J.Gregor, Cambridge, Cambridge University Press. . (1998). Critique of Pure Reason, translated by Paul Guyer and Allen W. Wood, Cambridge, Cambridge University Press.

Kemp Smith, Norman. (2003). A Commentary to Kant's Critique of Pure Reason, England, Palgrave Macmillan.

Liddell, B.E.A., (1970). Kant on the Foundation of Morality, Bloomington and London, Indian University Press.

Molasadra. (1981). Al-Hekme Al-Motealie Fi Al-Asfar Al-Aghlie Al-Arbae, Third edition. Beirut, Dar Ehya, Al-Toras Al-Arabi.

Molasadra. (1984). Mafatih Al-Qeib, Tahghigh Mohammad Khajavi, First edition. Tehran. Studies and cultural researches.

Molasadra. (1996). The philosophical theses. Tahghigh Hamed Naji Esfahani, First edition. Tehran. Hekmat publications.

Saragih, M. Yoserizal. (2018). Some Characteristics of Islamic Journalism Based on Al

Quran. Budapest International Research and Critics Institute (BIRCI-Journal), 01 